\title{
Cellular Injury of Cardiomyocytes during Hepatocyte Growth Factor Gene Transfection with Ultrasound-Triggered Bubble Liposome Destruction
}

\author{
Kazuo Komamura, ${ }^{1}$ Rie Tatsumi, ${ }^{1}$ Yuko Tsujita-Kuroda, ${ }^{1}$ Takatoshi Onoe, ${ }^{2}$ \\ Kunio Matsumoto, ${ }^{3}$ Toshikazu Nakamura, ${ }^{3}$ Jun-ichi Miyazaki, ${ }^{4}$ Takeshi Horio, ${ }^{5}$ \\ and Masaru Sugimachi ${ }^{1}$ \\ ${ }^{1}$ Department of Cardiovascular Dynamics, Research Institute, National Cerebral and Cardiovascular Center, 5-7-1 Fujishiro-dai, \\ Suita, Osaka 565-8565, Japan \\ ${ }^{2}$ Department of Nursing Science, Taisei Gakuin University, Sakai 587-8555, Japan \\ ${ }^{3}$ Division of Molecular Regenerative Medicine, Department of Biochemistry and Molecular Biology, \\ Osaka University Graduate School of Medicine, Suita 565-0871, Japan \\ ${ }^{4}$ Division of Stem Cell Regulation Research, G6, Osaka University School of Medicine, Suita 565-0871, Japan \\ ${ }^{5}$ Division of Hypertension, National Cerebral and Cardiovascular Center, Suita 565-8565, Japan
}

Correspondence should be addressed to Kazuo Komamura, kkoma@hsp.ncvc.go.jp

Received 6 August 2010; Accepted 31 October 2010

Academic Editor: Hasan Uludağ

Copyright (c) 2011 Kazuo Komamura et al. This is an open access article distributed under the Creative Commons Attribution License, which permits unrestricted use, distribution, and reproduction in any medium, provided the original work is properly cited.

\begin{abstract}
We transfected naked HGF plasmid DNA into cultured cardiomyocytes using a sonoporation method consisting of ultrasoundtriggered bubble liposome destruction. We examined the effects on transfection efficiency of three concentrations of bubble liposome $\left(1 \times 10^{6}, 1 \times 10^{7}, 1 \times 10^{8} / \mathrm{mL}\right)$, three concentrations of HGF DNA $(60,120,180 \mu \mathrm{g} / \mathrm{mL})$, two insonification times (30, $60 \mathrm{sec})$, and three incubation times $(15,60,120 \mathrm{~min})$. We found that low concentrations of bubble liposome and low concentrations of DNA provided the largest amount of the HGF protein expression by the sonoporated cardiomyocytes. Variation of insonification and incubation times did not affect the amount of product. Following insonification, cardiomyocytes showed cellular injury, as determined by a dye exclusion test. The extent of injury was most severe with the highest concentration of bubble liposome. In conclusion, there are some trade-offs between gene transfection efficiency and cellular injury using ultrasound-triggered bubble liposome destruction as a method for gene transfection.
\end{abstract}

\section{Introduction}

Ultrasound-triggered bubble liposome destruction (sonoporation) has been proposed as a safe nonviral means of gene therapy that can target many different cells or tissues. In the field of cardiovascular medicine, this method may have significant potential for the introduction of therapeutic genes directly into vascular cells or cardiomyocytes $[1,2]$. Sonoporation can only be clinically effective if the doseeffect relationship between the amount of bubble liposome and transfection efficiency is first established. However, few reports have already examined this dose-effect relationship and the safety of the procedure [3].

Transfection efficiency in sonoporation depends on various conditions including type of microbubble, mode of ultrasound, frequency of ultrasound, intensity of acoustic pressure, concentration of microbubble, dose of DNA, duration of insonification, incubation time of cell with DNA, repeat count of insonification, type of targeted cell, and other physicochemical conditions like temperature and carbon dioxide concentration, [3]. Greenleaf et al. reported that ultrasound acoustic pressure, DNA concentration, and 
repeat count of insonification correlated with transfection rate [4]. Teupe et al. demonstrated that duration of insonification did not affect transfection rate [5]. Then, Chen et al. showed that transfection rate reached plateau when DNA concentration was increased [6].

Greenleaf et al. also showed that transfection rate peaked and fell off according to the change in liposome concentration [4]. They thought it might be derived from cellular toxicity of large amount of liposome. Li et al. reported that cell viability decreased along with the increase in microbubble concentration [1]. Guo et al. demonstrated that cell viability decreased with the increase in duration of insonification [7]. Suzuki et al. and Li et al. showed that cell viability decreased with the increase in ultrasound acoustic pressure $[8,9]$.

On the basis of those previous findings, we planned to examine the effects of amount of plasmid DNA, liposome concentration, duration of insonification, repeat count of insonification, and time of incubation with liposome, cell, and DNA on transfection rate, which was measured by means of HGF protein release into culture medium.

\section{Materials and Methods}

2.1. Cell Culture. Primary cultures of neonatal ventricular myocytes were prepared as described previously [10]. Briefly, apical halves of cardiac ventricles from 1-day-old Wistar rats were separated, minced, and dispersed with $0.1 \%$ collagenase type II (Worthington Biochemical Corp., Freehold, $\mathrm{NJ})$. Myocytes were segregated from nonmyocytes using a discontinuous Percoll gradient (Sigma Chemical Co., Inc., St. Louis, MO). After centrifugation, the upper layer consisted of a mixed population of nonmyocyte cell types and the lower layer consisted almost exclusively of cardiac myocytes. After the myocytes had been incubated twice on uncoated 10$\mathrm{cm}$ culture dishes for 30 minutes to remove any remaining nonmyocytes, the nonattached viable cells were plated on gelatin-coated 24-well culture plates or 10-cm culture dishes and then cultured in DMEM (Life Technologies, Grand Island, NY) supplemented with 10\% FCS (Life Technologies, Grand Island, NY). After 24-hour incubation in DMEM with FCS, the culture medium was changed to serum-free DMEM, and all experiments were performed 24 hours later. This purification procedure has well been established [11, $12]$, and $>95 \%$ of the cells obtained by this method were cardiomyocytes.

2.2. Plasmid DNA. Preparation of rat hepatocyte growth factor (HGF) expression plasmid DNA was described previously [13]. Briefly, rat HGF cDNA cloned by polymerase chain reaction was inserted into the unique Xho I site between the cytomegalovirus immediate-early enhancer-chicken $\beta$ actin hybrid promoter and rabbit $\beta$-globin poly $\mathrm{A}$ site of the pCAGGS expression plasmid [14]. The resulting plasmid, pCAGGS-HGF, was grown in Escherichia coli DH5 $\alpha$ (Figure 1(a)). The plasmid was purified with a QUIAGEN plasmid DNA kit and dissolved in TE buffer. The purified plasmid DNA was stored at $-20^{\circ} \mathrm{C}$ and diluted to the required concentration with distilled water immediately before use.

2.3. Bubble Liposome. Liposome microbubble, SHU 508A, consists of palmitic acid and galactose and provides echogenic micron-sized air bubbles when suspended in water. The diameter of bubbles ranges from 2 to $8 \mu \mathrm{m}$, and $97 \%$ are smaller than $6 \mu \mathrm{m}$ [15]. These air bubbles are stabilized by palmitic acid, which forms a molecular film that lowers the surface tension of the aqueous vehicle. The SHU 508A bubbles are nontoxic, have a neutral $\mathrm{pH}$, are biodegradable, and are made from a physiologically occurring substance. The physiochemical properties of SHU 508A bubbles are typical of a saccharide solution [15].

2.4. Experiment on Ultrasound Mode. Before performing the experiments for dose-effect relationships using liposome sonoporation, we needed to determine the most appropriate ultrasound mode for the sonoporation procedure for efficient transfection. We tested four modes of ultrasound: pulsed wave Doppler, color flow Doppler, continuous wave Doppler, and harmonic power Doppler, which are available with standard echocardiographic machinery in a clinical laboratory. We performed a simple transfection experiment at the same acoustic pressure of $0.5 \mathrm{~W} / \mathrm{cm}^{2}$ for each ultrasound mode, using a single condition with $60 \mu \mathrm{g}$ HGF plasmid DNA, $1 \times 10^{7}$ particles $/ \mathrm{mL}$ of SHU 508A liposome, $30 \mathrm{sec}$ insonification, 15 min of DNA incubation, and 3 repetitions of insonification.

Rat neonatal cardiomyocytes were inoculated and grown to confluence in DMEM $+10 \%$ FCS. After confluence had been reached in a $35 \mathrm{~mm}$ Petri dish, the medium was changed to fresh defined serum-free medium. Plasmid DNA was diluted with distilled water immediately before the transfection. Each experiment was performed on 20 dishes. Cells on each dish were treated with ultrasound (Figure 1(b)). Pulsed wave Doppler, color flow Doppler, and continuous wave Doppler were insonified from PSK-25AT acoustic transducer with Toshiba SSA-380A (Toshiba Medical Systems), and harmonic power Doppler was insonified from S3 transducer with Sonos 5500 (Phillips Medical Systems). The experimental results are shown in Figure 2. Continuous-wave Doppler ultrasound was the most efficacious and was used for subsequent experiments.

2.5. Experiments for Dose-Effect Relations. The medium in $35 \mathrm{~mm}$ Petri dishes containing the cardiomyocytes was changed to fresh defined serum-free medium from DMEM+10\% FCS. Rat HGF plasmid DNA was diluted with distilled water, and a volume corresponding to 60,120 , or $180 \mu \mathrm{g}$ was added to each of the 20 Petri dishes per DNA dose. Cells on each dish were then treated with continuous-wave Doppler ultrasound (frequency of $2.5 \mathrm{MHz}$ and acoustic intensity of $0.5 \mathrm{~W} / \mathrm{cm}^{2}$ from a PSK-25AT acoustic transducer with Toshiba SSA-380A Ultrasound system) with SHU 508A liposome $\left(1 \times 10^{7}\right.$ particles $\left./ \mathrm{mL}\right)$ for acoustic exposure time of 30 or 60 seconds at room temperature (Figure 1(b)). In a separate series of experiments, we tested four liposome 


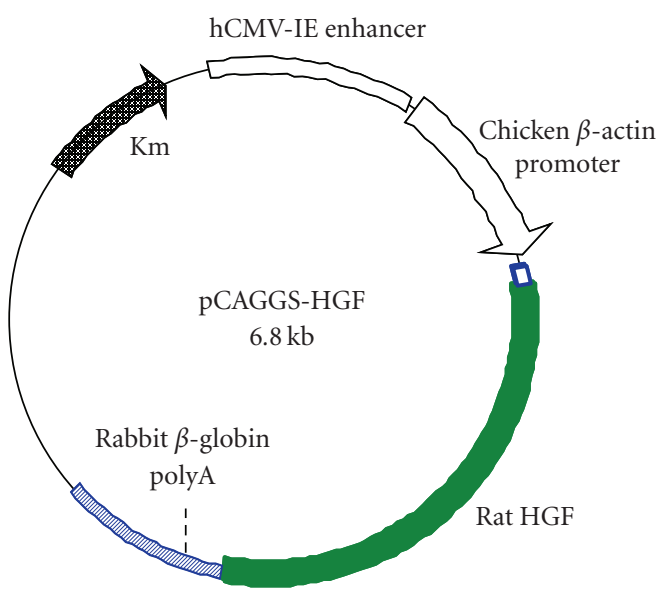

(a)

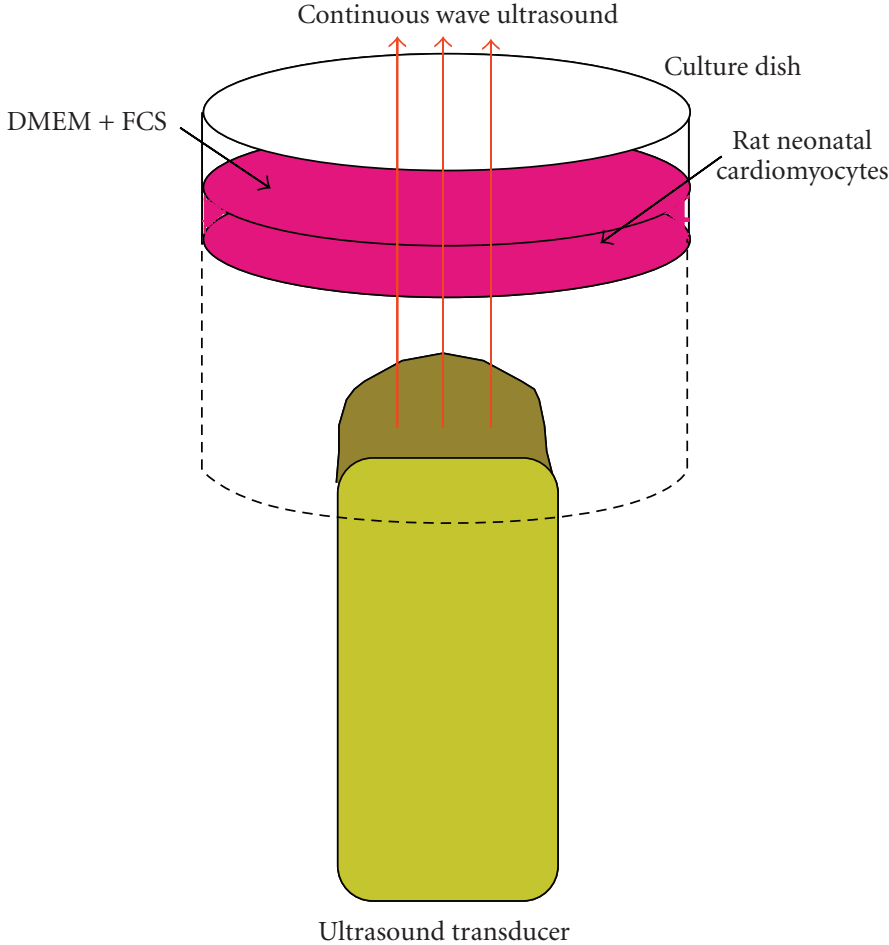

(b)

Figure 1: (a) Structure of the expression plasmid pCAGGS-HGF. The expression cassette of pCAGGS-HGF contains chicken $\beta$-actin promoter, rat HGF, and rabbit $\beta$-globin poly A. (b) Experimental setup. The transducer was attached to the bottom of the dish.

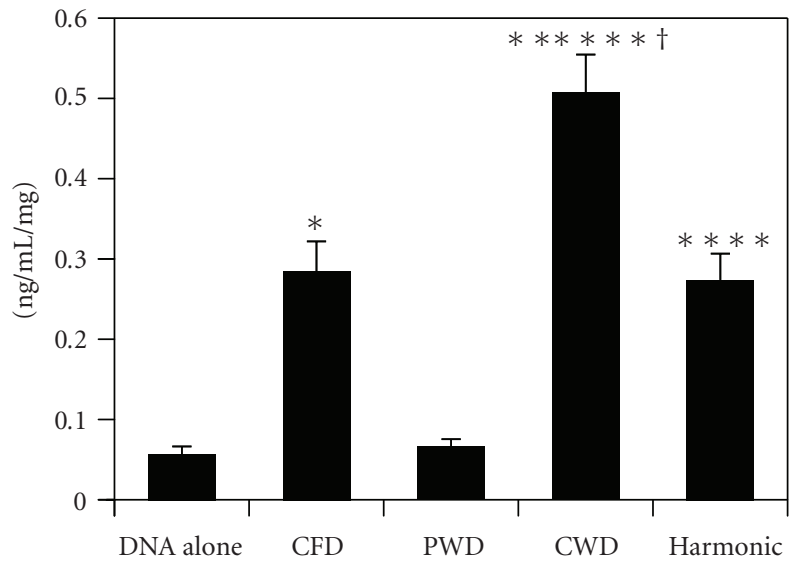

Figure 2: Comparison of four modes of ultrasound for sonoporation. Cells treated with continuous-wave Doppler ultrasound yielded the largest amount of HGF protein indicating this to be the most effective ultrasound mode. CFD: color flow Doppler; PWD: pulsed wave Doppler; CWD: continuous wave Doppler; Harmonic: harmonic power Doppler. ${ }^{*} P<.05$ versus DNA alone; ${ }^{* *} P<.05$ versus CFD; ${ }^{* * *} P<.05$ versus $P W D ;{ }^{\dagger} P<.05$ versus Harmonic.

concentrations $\left(0,1 \times 10^{6}, 1 \times 10^{7}\right.$ or $1 \times 10^{8}$ particles $\left./ \mathrm{mL}\right)$, three insonification repetitions ( 1 insonification only, 3 or 5 insonifications for 30 seconds), and three DNA incubation times (15, 60 or $120 \mathrm{~min})$. After the incubation, the culture medium was changed to normal DMEM $+10 \%$ FCS and the cells were cultured for 72 hours. In a separate set of experiments, we examined the effect of culture period on the amount of DNA product that is HGF protein by discontinuing culture at 24,48 , and 72 hours and measuring the amount of rat HGF protein in the medium. The total amount of protein content in the cultured cells was measured and used to correct the HGF level in each dish. We measured rat HGF protein using an EIA kit (Institute of Immunology Co., Ltd., Tokyo, Japan) [13] and protein content of cultured cells using a Modified Lowry Protein Assay Kit (Pierce Biotechnology, Rockford).

2.6. Viability of Cultured Cells. To determine the safety of sonoporation, in a separate experiment, cultured cells were exposed to $0.1 \%$ trypan blue for $5 \mathrm{~min}$ just after ultrasound insonification. This allowed assessment of sarcolemmal membrane damage and was performed for each concentration of liposome, each insonification time, and each number of repetitions of insonification. The number of stained and unstained cells in the dishes was counted and used to calculate the percentage of intact cells [16]. The degree of cellular injury caused by sonoporation was determined by examining the insonified cells by scanning electron microscopy (Hitachi S-4800). Immediately after ultrasound insonification in the presence of liposome, the cardiomyocytes were fixed with phosphate-buffered $2.5 \%$ glutaraldehyde for 4 hours, followed by postfixation with $1 \%$ 
osmium tetroxide for 1 hour, and then were conventionally prepared for scanning electron microscopy.

2.7. Statistical Analysis. Data were expressed as the mean \pm SEM. Comparisons of parameters from experimental groups were performed with unpaired $t$ tests and resulting $P$ values were corrected according to the Bonferroni method. In analyses, $P<.05$ was considered to indicate statistical significance.

\section{Results}

3.1. Effect of Culture Period on HGF Protein Production by Sonoporated Cardiomyocytes. The concentration of HGF protein in the culture medium increased as the culture period after ultrasonic transfection was extended. The transfection consisted of three 30-sec insonifications a 15-min incubation with HGF DNA $(60 \mu \mathrm{g})$ and liposome $\left(1 \times 10^{7}\right.$ particle $\left./ \mathrm{mL}\right)$ (Figure 3(a)). After 72 hours of culture, HGF protein concentration in the culture medium was measured and corrected using the protein content of the cultured cells.

\subsection{Effect of the Amount of Plasmid DNA on HGF Protein Pro-} duction by Sonoporated Cardiomyocytes. HGF protein concentration in the culture medium was $0.54 \pm 0.049 \mathrm{ng} / \mathrm{mL} / \mathrm{mg}$ and was highest when $60 \mu \mathrm{g}$ of DNA was administered with a liposome concentration of $1 \times 10^{7}$ particles $/ \mathrm{mL}$, a15-min incubation, and three $30-\mathrm{sec}$ insonification. Although the nominal mean values of HGF protein after transfection of 120 and $180 \mu \mathrm{g}$ DNA were lower than those after transfection of $60 \mu \mathrm{g}$, the differences were not statistically significant (Figure 3(b)).

3.3. Effect of Incubation Period with Plasmid DNA and Liposome on HGF Protein Production by Sonoporated Cardiomyocytes. HGF protein concentration in the culture medium was $0.56 \pm 0.053 \mathrm{ng} / \mathrm{mL} / \mathrm{mg}$ and was highest when the incubation time was $15 \mathrm{~min}$ with a liposome concentration of $1 \times 10^{7}$ particles $/ \mathrm{mL}, 60 \mu \mathrm{g}$ DNA, and three $30-\mathrm{sec}$ insonification. Although the mean values of HGF protein after transfection for 60 and $120 \mathrm{~min}$ were lower than those after $15 \mathrm{~min}$ incubation, the differences were not statistically significant (Figure 3(c)).

3.4. Effect of Insonification Time on HGF Protein Production by Sonoporated Cardiomyocytes. HGF protein concentration in the culture medium was $0.59 \pm 0.052 \mathrm{ng} / \mathrm{mL} / \mathrm{mg}$ and was highest when the insonification period was $30 \mathrm{sec}$ with $60 \mu \mathrm{g}$ DNA, a liposome concentration of $1 \times 10^{7}$ particles $/ \mathrm{mL}$, and 15-min incubation. There was no significant difference in HGF production in cells insonified for 30 and $60 \mathrm{~min}$ (Figure 3(d)).

\subsection{Effect of Liposome Concentration on HGF Protein Produc-} tion by Sonoporated Cardiomyocytes. HGF protein concentration in the culture medium was $0.53 \pm 0.053 \mathrm{ng} / \mathrm{mL} / \mathrm{mg}$ and was nominally highest when the liposome concentration was $1 \times 10^{7}$ particles/mL and insonification consisted of three 30 -sec ultrasound exposures, though it was statistically similar to that obtained with $1 \times 10^{6}$ particles $/ \mathrm{mL}$. At a higher liposome concentration of $1 \times 10^{8}$ particles/mL, HGF protein concentration decreased (Figure 3(e)).

3.6. Effect of Repetition of Insonification on HGF Protein Production by Sonoporated Cardiomyocytes. HGF protein concentration in the culture medium was $0.54 \pm 0.053 \mathrm{ng} / \mathrm{mL} /$ $\mathrm{mg}$ and was highest when three 30 -sec insonifications were given, with a liposome concentration of $1 \times 10^{7}$ particles $/ \mathrm{mL}$ and $60 \mathrm{mg}$ DNA. This protein production was statistically higher than in cells given one or five insonifications (Figure 3(f)).

3.7. Effect of Insonification Time on Cell Viability. The percentage of dead cells was $14.7 \pm 0.9 \%$ and was higher in the cells given five $30-\mathrm{sec}$ insonifications at a liposome concentration of $1 \times 10^{7}$ particles $/ \mathrm{mL}$ (Figure $4(\mathrm{a})$ ). There was no statistical difference between 30 - and 60-sec insonification.

3.8. Effect of Liposome Concentration on Cell Viability. The percentage of dead cells increased with increasing concentrations of liposome (Figure 4(b)). The dead cell count was $24.8 \pm 2.9 \%$ and was highest when the liposome concentration was $1 \times 10^{8}$ particles $/ \mathrm{mL}$ and three 30 -sec insonifications were used.

3.9. Effect of Number of Insonification Repetitions on Cell Viability. The percentage of dead cells increased as the number of insonification repetitions increased (Figure 4(c)). The dead cell count was $14.7 \pm 0.9 \%$ and was highest when five repetitions of the insonification step were given, with a liposome concentration of $1 \times 10^{7}$ particles $/ \mathrm{mL}$.

3.10. Scanning Electron Microscopy Observations of Sonoporated Cardiomyocytes. No particular changes were evident on the surfaces of untreated control cultured cardiomyocytes when viewed with the scanning electron microscope at low and high magnification (Figures 5(a) and 5(b)). After sonoporation with a low concentration of liposome (Figure 5(c)) and with a high concentration of liposome (Figure 5(d)), microdimples or pores were observed on the surfaces of the cultured cardiomyocytes.

\section{Discussion}

Considerable efforts have been made to develop methods that will allow effective and safe introduction of vectors into cells for gene therapy. However, we still need a breakthrough in the form of a novel vector that will transform cells at high efficiency and with low risk of adverse effects. This is especially true in cardiovascular medicine, where malignant cellular transformation is rare [17]. One of the promising candidates for safe and efficacious gene transfection is a naked plasmid vector that has been modified to have high affinity for cardiovascular tissues but which has no builtin viral components $[17,18]$. We have developed a method for electroporation of a cytokine gene for treatment of 


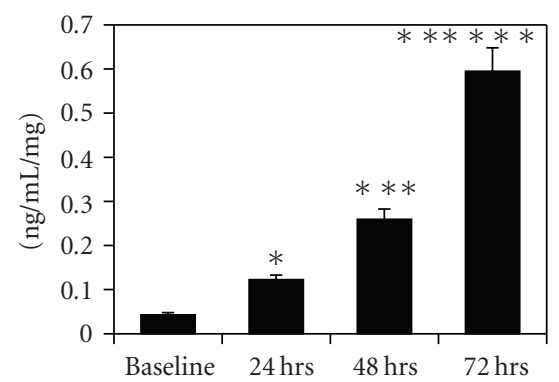

(a)

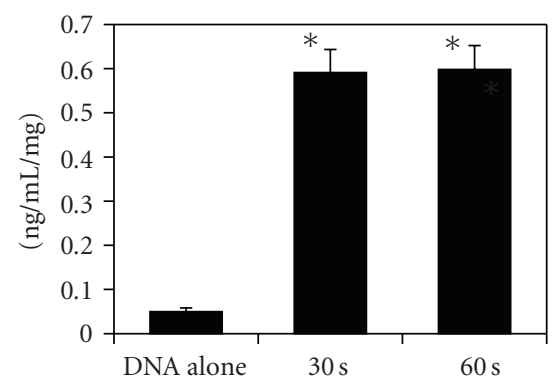

(d)

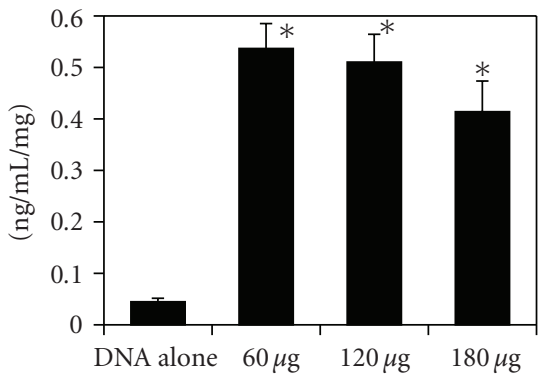

(b)

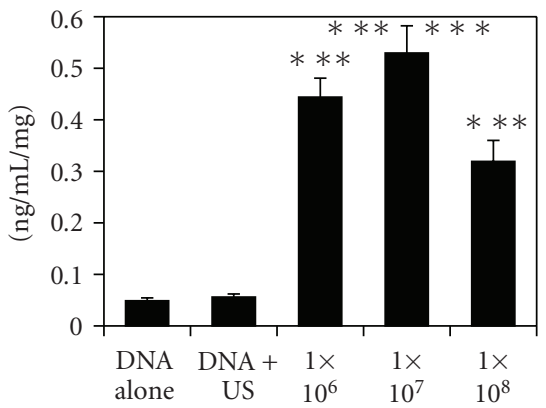

(e)

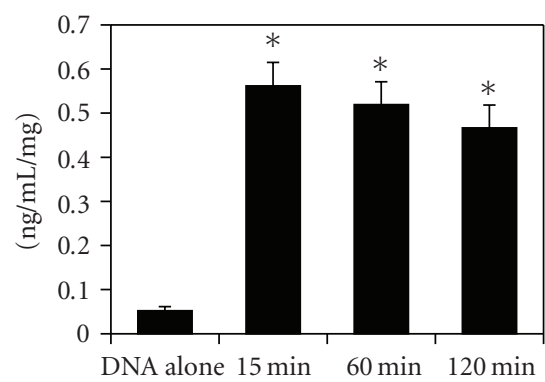

(c)

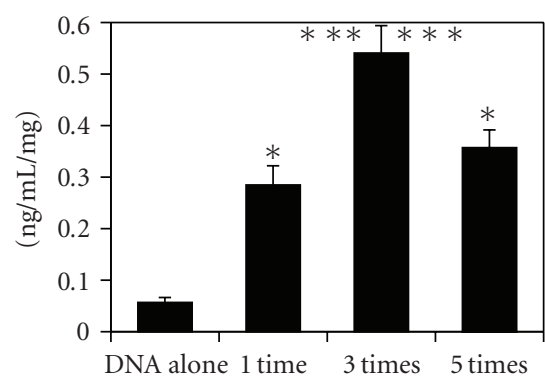

(f)

FIGURE 3: (a) Effect of culture period after transfection of HGF DNA on HGF protein production using $60 \mu \mathrm{g}$ of DNA and $1 \times 10^{7}$ particles/mL liposome with three 30-sec insonifications and 15-min incubation with DNA. Baseline was the concentration of rat HGF protein in the culture medium around rat cardiomyocytes without any intervention at the beginning of cell culture. ${ }^{*} P<.05$ versus baseline; ${ }^{* *} P<$ .05 versus 24 hours after the onset of culture; ${ }^{* *} P<.05$ versus 48 hours after the onset of culture. (b) Effect of amount of plasmid DNA on HGF protein production using $1 \times 10^{7}$ particles/mL liposome with three 30 -sec insonifications and 15-min incubation with DNA. "DNA alone" indicates the concentration of rat HGF protein in the culture medium of cardiomyocytes treated with $60 \mu \mathrm{g}$ DNA without insonification. ${ }^{*} P<.05$ versus DNA alone. (c) Effect of incubation period of cardiomyocytes with plasmid DNA and liposome on HGF protein production using $60 \mu \mathrm{g}$ of DNA and $1 \times 10^{7}$ particles $/ \mathrm{mL}$ liposome with three 30 -sec insonifications. ${ }^{*} P<.05$ versus DNA alone. (d) Effect of insonification time on protein production using $60 \mu \mathrm{g}$ of DNA, $1 \times 10^{7}$ particles/mL liposome, and 15 -min incubation with DNA, and three 30 - or 60 -sec insonifications. ${ }^{*} P<.05$ versus DNA alone. (e) Effect of liposome concentration on HGF protein production using $60 \mu \mathrm{g}$ of DNA with three 30 -sec insonifications and 15 -min incubation with DNA. $* P<.05$ versus DNA alone; $* * P<.05$ versus 0 particles $/ \mathrm{mL}$; ${ }^{* * *} P<.05$ versus $1 \times 10^{8}$ particles/mL. (f) Effect of repetition of insonification on HGF protein production using $6 \mu \mathrm{g}$ of DNA and $1 \times 10^{7}$ particles/mL liposome with 15 -min incubation with DNA. ${ }^{*} P<.05$ versus DNA alone; ${ }^{* *} P<.05$ versus 1 time; ${ }^{* * *} P<.05$ versus 5 times.

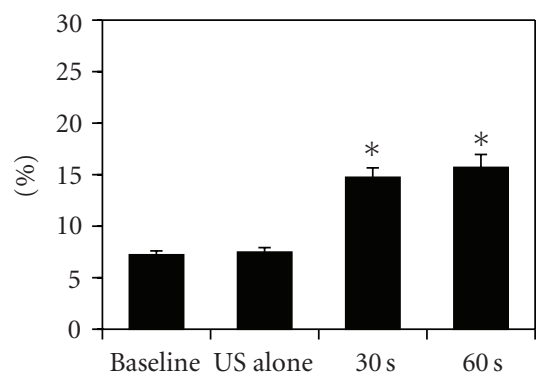

(a)

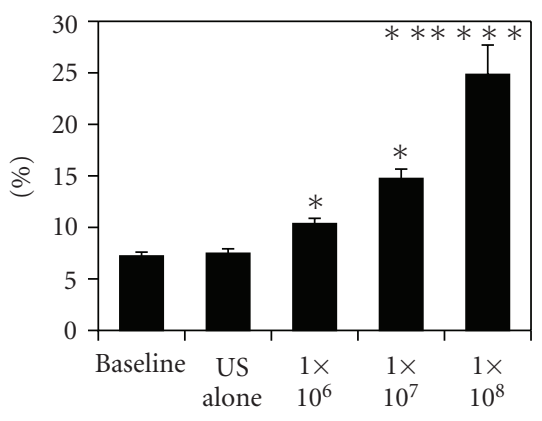

(b)

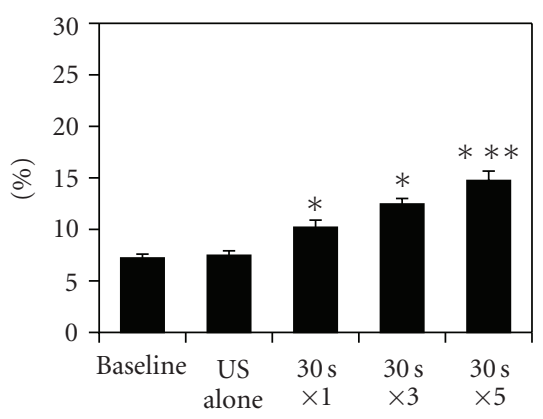

(c)

FIgURE 4: (a) Effect of insonification time on cell viability using $60 \mu \mathrm{g}$ of DNA, $1 \times 10^{7}$ particles/mL liposome, and 15 -min incubation with DNA, and three 30- or 60-sec insonifications. "US alone" represents the percentage of dead cells immediately after three 30-sec insonifications in the absence of liposome and DNA. ${ }^{*} P<.05$ versus baseline. (b) Effect of liposome concentration on cell viability using $60 \mu \mathrm{g}$ of DNA and three 30 -sec insonifications and 15 -min incubation with DNA. ${ }^{*} P<.05$ versus baseline; ${ }^{* *} P<.05$ versus $1 \times 10^{6}$ particles/mL; ${ }^{* * *} P<.05$ versus $1 \times 10^{8}$ particles $/ \mathrm{mL}$. (c) Effect of repetitions of insonification on cell viability using $60 \mu \mathrm{g}$ of DNA, $1 \times 10^{7}$ particles $/ \mathrm{mL}$ liposome, and 15 -min incubation with DNA. ${ }^{*} P<.05$ versus baseline; ${ }^{* *} P<.05$ versus $30 \mathrm{sec} \times 1$. 


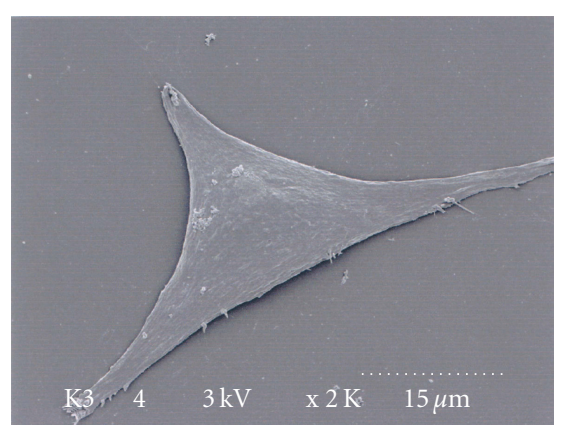

(a)

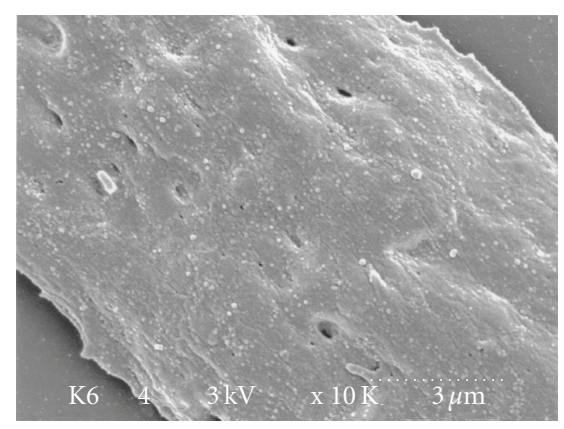

(c)

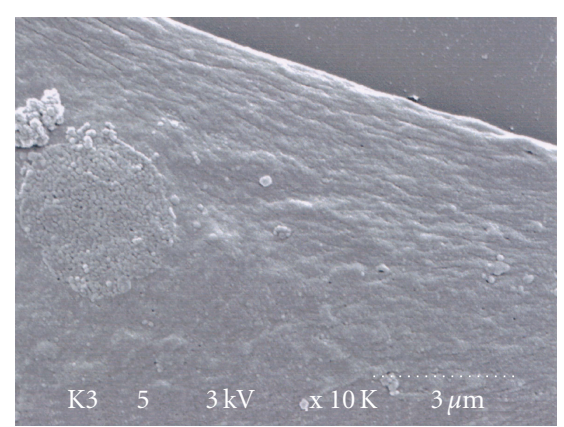

(b)

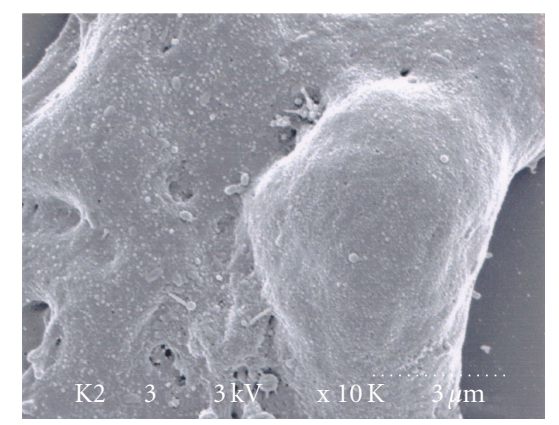

(d)

Figure 5: (a) and (b) Scanning electron microscopic images of intact cell surfaces of cultured cardiomyocytes. Scale dots are indicated on the images. (c) Image of a cell surface immediately after sonoporation using $1 \times 10^{6}$ particles/mL liposome. (d) Image of a cell surface immediately after sonoporation using $1 \times 10^{8}$ particles $/ \mathrm{mL}$ liposome.

cardiomyopathy [13]. However, using electric shock for transfection is not clinically practical. For this reason, we are pursuing the present sonoporation method as a protocol for gene transfection.

The HGF protein used in the present study is found in a wide variety of cell types and has multiple biological properties, including mitogenic, motogenic, morphogenic and antiapoptotic activities [19]. Several lines of evidence indicate that this molecule has potential for therapeutic use for treatment of heart failure, myocardial infarction, angina, and hypertension [20-22]. HGF may also have enormous therapeutic potential for hepatic and renal disorders, in addition to cardiovascular diseases [23-26].

In the present study, we showed variations in amount of HGF plasmid DNA, liposome concentration, the duration of insonification, and incubation time of the cardiomyocytes with liposome and DNA, and their dose relationships with the final amount of HGF protein released from the cultured neonatal cardiomyocytes. We found that specific amounts of liposome and repetitions of insonification were needed for effective protein production from cardiomyocytes. However, high concentrations of bubble liposome and large numbers of repeat insonifications resulted in decreased cell viability.

Plasma membrane sonoporation induced by ultrasound and subsequent self-sealing has been reported in previous investigations [27-29]. However, the exact mechanism by which membrane sonoporation causes substance incorporation into the cell is not yet understood. Some investigators speculate that the membrane poration results in both transfection efficiency and cellular damage. In the present study, scanning microscopy images revealed some microdimples or pores on the cell surface after sonoporation, which did not exist on the surface of control cardiomyocytes. The numbers of dimples or pores tended to increase with higher concentrations of liposome. Thus, we speculate that these dimples or pores on the cell surface might be related to transfection efficiency and might be evidence of cellular injury by sonoporation. Previous studies of sonoporation of vascular walls revealed that microbubble destruction would cause rupture of microvessels and extravasation [30-33], which would cancel out some benefits of sonoporation. Thus, the poration and self-sealing mechanism needs to be fully investigated and optimized.

A sonoporation technique targeting the cardiovascular system has now been developed for gene transfection to myocardium, limb skeletal muscle, and arteries [34-37]. For a variety of target tissues, a number of microbubbles, including liposomes, and a range of ultrasound modes have been developed. The optimal combination of the type of microbubble, ultrasound mode, and target tissue still needs to be resolved [38-40]. However, the principal types of ultrasound used for sonoporation have included pulsed wave Doppler or continuous wave Doppler with acoustic pressure ranging $0.5-5 \mathrm{~W} / \mathrm{cm}^{2}$ [34-37]. In the present study, we found that continuous wave Doppler at a standard frequency for clinical use, that is, $2.5 \mathrm{MHz}$ and the usual acoustic pressure of $0.5 \mathrm{~W} / \mathrm{cm}^{2}$, was most effective with our cardiomyocytes. 
The reason we used one of the standard ultrasound modes with standard settings for clinical use is that we would like to use our sonoporation system eventually in a clinical setting.

The present study has several limitations. To avoid the complexity of numerous combinations of experimental conditions, such as amount of DNA, concentration of liposome, duration of insonification, repeat count of insonification, length of incubation time, and culture period after gene transfection, we only used several practical combinations for an in vitro experiment for cultured cardiomyocytes. Thus, we might have missed other multimodal aspects of dose-effect relationships among these conditions.

\section{Conclusion}

HGF DNA was successfully transferred to cultured cardiomyocytes using sonoporation with a defined liposome concentration and a mode of insonification. A number of trade-offs between transfection efficiency and cellular injury have to be balanced to optimize this sonoporation method.

\section{Acknowledgments}

This study was supported by a Grant-in-Aid for Scientific Research 14570709 from the Ministry of Education, Culture, Sport, Science, and Technology of Japan and by the Program for Promotion of Fundamental Studies in Health Sciences of the Pharmaceuticals and Medical Devices Agency (PMDA).

\section{References}

[1] T. Li, K. Tachibana, M. Kuroki, and M. Kuroki, "Gene transfer with echo-enhanced contrast agents: comparison between Albunex, Optison, and Levovist in mice-initial results," Radiology, vol. 229, no. 2, pp. 423-428, 2003.

[2] S. Tsunoda, O. Mazda, Y. Oda et al., "Sonoporation using microbubble BR14 promotes pDNA/siRNA transduction to murine heart," Biochemical and Biophysical Research Communications, vol. 336, no. 1, pp. 118-127, 2005.

[3] L. B. Feril Jr. and T. Kondo, "Biological effects of low intensity ultrasound: the mechanism involved, and its implications on therapy and on biosafety of ultrasound," Journal of Radiation Research, vol. 45, no. 4, pp. 479-489, 2004.

[4] W. J. Greenleaf, M. E. Bolander, G. Sarkar, M. B. Goldring, and J. F. Greenleaf, "Artificial cavitation nuclei significantly enhance acoustically induced cell transfection," Ultrasound in Medicine and Biology, vol. 24, no. 4, pp. 587-595, 1998.

[5] C. Teupe, S. Richter, B. Fisslthaler et al., "Vascular gene transfer of phosphomimetic endothelial nitric oxide synthase (S1177D) using ultrasound-enhanced destruction of plasmidloaded microbubbles improves vasoreactivity," Circulation, vol. 105, no. 9, pp. 1104-1109, 2002.

[6] S. Chen, R. V. Shohet, R. Bekeredjian, P. Frenkel, and P. A. Grayburn, "Optimization of ultrasound parameters for cardiac gene delivery of adenoviral or plasmid deoxyribonucleic acid by ultrasound-targeted microbubble destruction," Journal of the American College of Cardiology, vol. 42, no. 2, pp. 301308, 2003.

[7] D.-P. Guo, X.-Y. Li, P. Sun et al., "Ultrasound-targeted microbubble destruction improves the low density lipoprotein receptor gene expression in HepG2 cells," Biochemical and
Biophysical Research Communications, vol. 343, no. 2, pp. 470474, 2006.

[8] R. Suzuki, T. Takizawa, Y. Negishi, N. Utoguchi, and K. Maruyama, "Effective gene delivery with novel liposomal bubbles and ultrasonic destruction technology," International Journal of Pharmaceutics, vol. 354, no. 1-2, pp. 49-55, 2008.

[9] H. L. Li, X. Z. Zheng, H. P. Wang, F. Li, Y. Wu, and L. F. $\mathrm{Du}$, "Ultrasound-targeted microbubble destruction enhances $\mathrm{AAV}$-mediated gene transfection in human RPE cells in vitro and rat retina in vivo," Gene Therapy, vol. 16, no. 9, pp. 1146$1153,2009$.

[10] T. Horio, T. Nishikimi, F. Yoshihara, H. Matsuo, S. Takishita, and K. Kangawa, "Inhibitory regulation of hypertrophy by endogenous atrial natriuretic peptide in cultured cardiac myocytes," Hypertension, vol. 35, no. 1, part 1, pp. 19-24, 2000.

[11] J.-S. Zheng, M. O. Boluyt, L. O’Neill, M. T. Crow, and E. G. Lakatta, "Extracellular ATP induces immediate-early gene expression but not cellular hypertrophy in neonatal cardiac myocytes," Circulation Research, vol. 74, no. 6, pp. 1034-1041, 1994.

[12] M. Harada, H. Itoh, O. Nakagawa et al., "Significance of ventricular myocytes and nonmyocytes interaction during cardiocyte hypertrophy: evidence for endothelin-1 as a paracrine hypertrophic factor from cardiac nonmyocytes," Circulation, vol. 96, no. 10, pp. 3737-3744, 1997.

[13] K. Komamura, R. Tatsumi, J.-I. Miyazaki et al., "Treatment of dilated cardiomyopathy with electroporation of hepatocyte growth factor gene into skeletal muscle," Hypertension, vol. 44, no. 3, pp. 365-371, 2004.

[14] K. Matsumoto and T. Nakamura, "Hepatocyte growth factor (HGF) as a tissue organizer for organogenesis and regeneration," Biochemical and Biophysical Research Communications, vol. 239, no. 3, pp. 639-644, 1997.

[15] B. B. Goldberg, JI. B. Liu, and F. Forsberg, "Ultrasound contrast agents: a review," Ultrasound in Medicine and Biology, vol. 20, no. 4, pp. 319-333, 1994.

[16] S. Kato, G. Takemura, R. Maruyama et al., "Apoptosis, rather than oncosis, is the predominant mode of spontaneous death of isolated adult rat cardiac myocytes in culture," Japanese Circulation Journal, vol. 65, no. 8, pp. 743-748, 2001.

[17] O. J. Müller, H. A. Katus, and R. Bekeredjian, "Targeting the heart with gene therapy-optimized gene delivery methods," Cardiovascular Research, vol. 73, no. 3, pp. 453-462, 2007.

[18] C. A. Holladay, T. O’Brien, and A. Pandit, "Non-viral gene therapy for myocardial engineering," Wiley Interdisciplinary Reviews: Nanomedicine and Nanobiotechnology, vol. 2, no. 3, pp. 232-248, 2010.

[19] K. Matsumoto and T. Nakamura, "Hepatocyte growth factor (HGF) as a tissue organizer for organogenesis and regeneration," Biochemical and Biophysical Research Communications, vol. 239, no. 3, pp. 639-644, 1997.

[20] K. Matsumoto and T. Nakamura, "HGF: its organotrophic role and therapeutic potential," CIBA Foundation Symposia, no. 212, pp. 198-211, 1997.

[21] N. Tomita, R. Morishita, J. Higaki, and T. Ogihara, "Novel molecular therapeutic approach to cardiovascular disease based on hepatocyte growth factor," Journal of Atherosclerosis and Thrombosis, vol. 7, no. 1, pp. 1-7, 2000.

[22] K. Komamura, J. Miyazaki, E. Imai, K. Matsumoto, T. Nakamura, and M. Hori, "Hepatocyte growth factor gene therapy for hypertension," Methods in Molecular Biology, vol. 423, pp. 393-404, 2008.

[23] K.-I. Kosai, K. Matsumoto, S. Nagata, Y. Tsujimoto, and T. Nakamura, "Abrogation of Fas-induced fulminant hepatic 
failure in mice by hepatocyte growth factor," Biochemical and Biophysical Research Communications, vol. 244, no. 3, pp. 683690, 1998.

[24] T. Ueki, Y. Kaneda, H. Tsutsui et al., "Hepatocyte growth factor gene therapy of liver cirrhosis in rats," Nature Medicine, vol. 5, no. 2, pp. 226-230, 1999.

[25] S. Mizuno, K. Matsumoto, and T. Nakamura, "HGF as a renotrophic and anti-fibrotic regulator in chronic renal disease," Frontiers in Bioscience, vol. 13, pp. 7072-7086, 2008.

[26] K. Matsumoto and T. Nakamura, "Hepatocyte growth factor: renotropic role and potential therapeutics for renal diseases," Kidney International, vol. 59, no. 6, pp. 2023-2038, 2001.

[27] K. Tachibana, T. Uchida, K. Ogawa, N. Yamashita, and K. Tamura, "Induction of cell-membrane porosity by ultrasound," The Lancet, vol. 353, no. 9162, p. 1409, 1999.

[28] S. Mehier-Humbert, T. Bettinger, F. Yan, and R. H. Guy, "Plasma membrane poration induced by ultrasound exposure: implication for drug delivery," Journal of Controlled Release, vol. 104, no. 1, pp. 213-222, 2005.

[29] F. Yang, N. Gu, D. Chen et al., "Experimental study on cell selfsealing during sonoporation," Journal of Controlled Release, vol. 131, no. 3, pp. 205-210, 2008.

[30] D. M. Skyba, R. J. Price, A. Z. Linka, T. C. Skalak, and S. Kaul, "Direct in vivo visualization of intravascular destruction of microbubbles by ultrasound and its local effects on tissue," Circulation, vol. 98, no. 4, pp. 290-293, 1998.

[31] J. Song, J. C. Chappell, M. Qi, E. J. VanGieson, S. Kaul, and R. J. Price, "Influence of injection site, microvascular pressure and ultrasound variables on microbubble-mediated delivery of microspheres to muscle," Journal of the American College of Cardiology, vol. 39, no. 4, pp. 726-731, 2002.

[32] S. Hernot and A. L. Klibanov, "Microbubbles in ultrasoundtriggered drug and gene delivery," Advanced Drug Delivery Reviews, vol. 60, no. 10, pp. 1153-1166, 2008.

[33] M. R. Böhmer, C. H. T. Chlon, B. I. Raju, C. T. Chin, T. Shevchenko, and A. L. Klibanov, "Focused ultrasound and microbubbles for enhanced extravasation," Journal of Controlled Release, vol. 148, no. 1, pp. 18-24, 2010.

[34] I. Rosenthal, J. Z. Sostaric, and P. Riesz, "Sonodynamic therapya review of the synergistic effects of drugs and ultrasound," Ultrasonics Sonochemistry, vol. 11, no. 6, pp. 349-363, 2004.

[35] J. M. Tsutsui, F. Xie, and R. T. Porter, "The use of microbubbles to target drug delivery," Cardiovascular Ultrasound, vol. 2, article 23, 2004.

[36] C. M. H. Newman and T. Bettinger, "Gene therapy progress and prospects: ultrasound for gene transfer," Gene Therapy, vol. 14, no. 6, pp. 465-475, 2007.

[37] C. R. Mayer and R. Bekeredjian, "Ultrasonic gene and drug delivery to the cardiovascular system," Advanced Drug Delivery Reviews, vol. 60, no. 10, pp. 1177-1192, 2008.

[38] S. Hernot and A. L. Klibanov, "Microbubbles in ultrasoundtriggered drug and gene delivery," Advanced Drug Delivery Reviews, vol. 60, no. 10, pp. 1153-1166, 2008.

[39] S. Tinkov, R. Bekeredjian, G. Winter, and C. Coester, "Microbubbles as ultrasound triggered drug carriers," Journal of Pharmaceutical Sciences, vol. 98, no. 6, pp. 1935-1961, 2009.

[40] C.-Y. Lin, T.-M. Liu, C.-Y. Chen et al., "Quantitative and qualitative investigation into the impact of focused ultrasound with microbubbles on the triggered release of nanoparticles from vasculature in mouse tumors," Journal of Controlled Release, vol. 146, no. 3, pp. 291-298, 2010. 

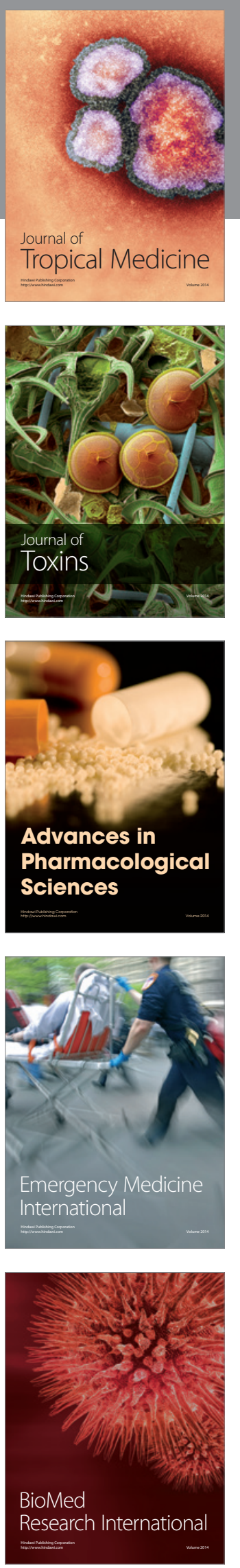
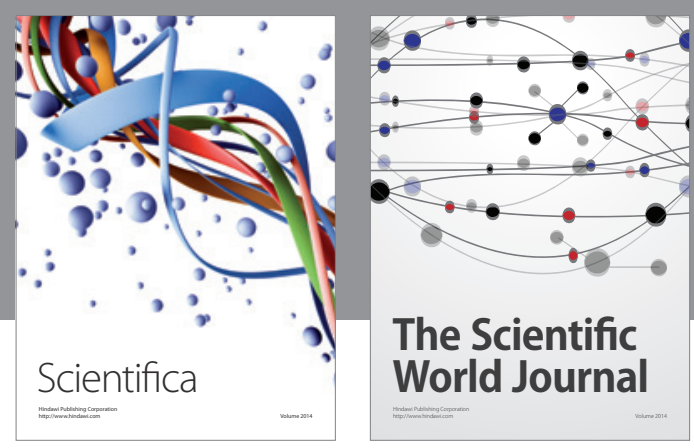

The Scientific World Journal
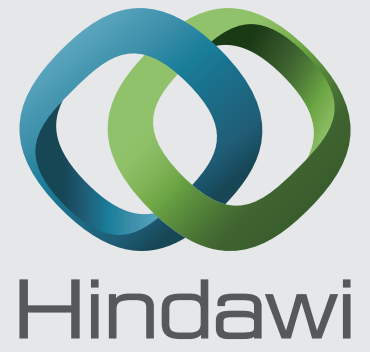

Submit your manuscripts at

http://www.hindawi.com
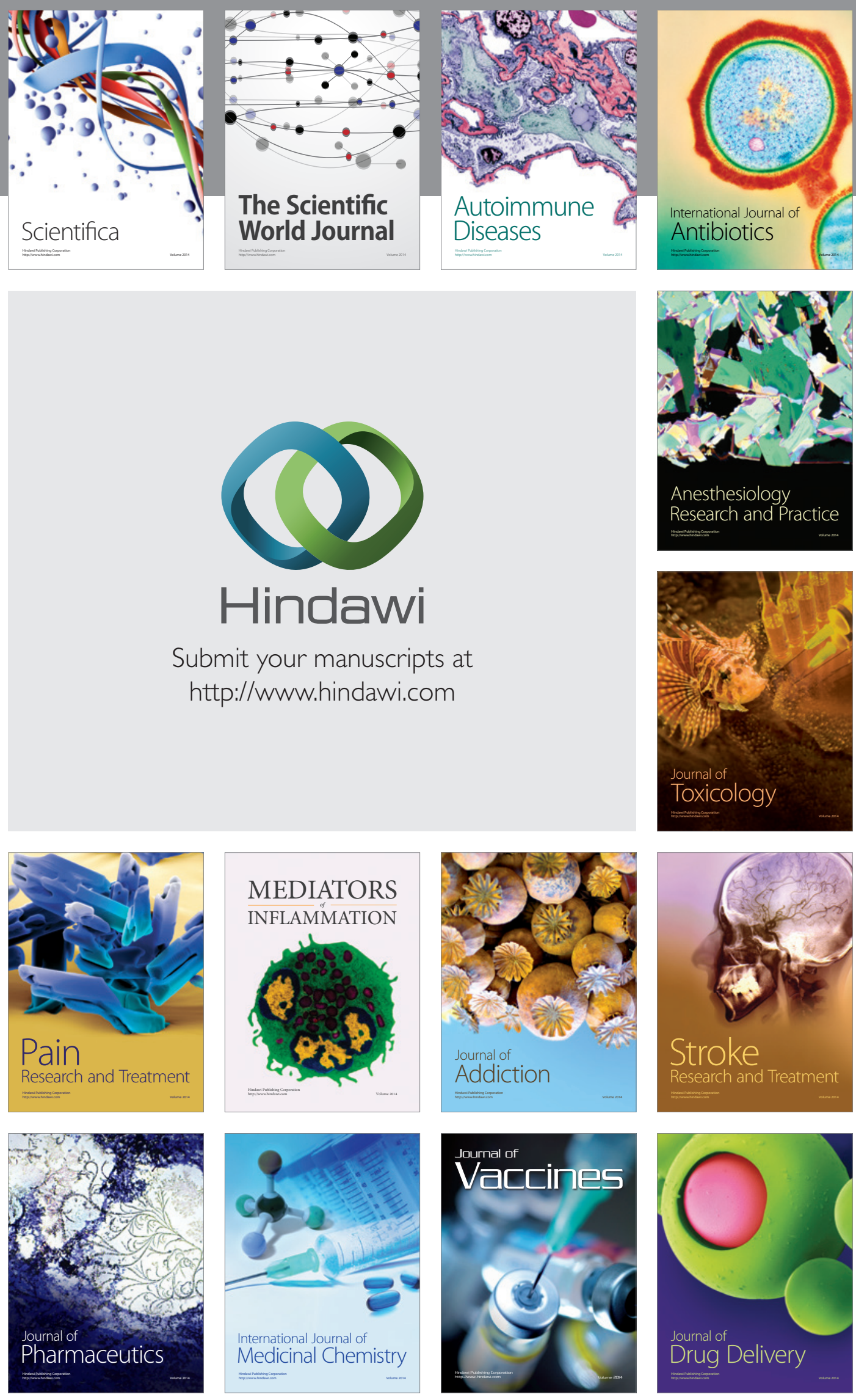